\title{
Discussion on Road Traffic Problems and "Public Transport Priority" Policy in the Macau Peninsula
}

\author{
Ziwei Huang \\ Faculty of Innovation and Design, The City University of Macau, Macau, China \\ Email: U19091105101@cityu.mo
}

How to cite this paper: Huang, Z.W. (2020) Discussion on Road Traffic Problems and "Public Transport Priority" Policy in the Macau Peninsula. World Journal of Engineering and Technology, 8, 631-641. https://doi.org/10.4236/wjet.2020.84044

Received: February 25, 2020

Accepted: October 28, 2020

Published: November 4, 2020

\begin{abstract}
The roads on the Macao Peninsula are famous for their short, fast, and small features. At the same time, due to the protection of historical and cultural sites, the road network system is mostly based on the planning and design of the previous road network system. Although the planning of the contemporary road network system is quite unique, it has not been considered to the contemporary transporting needs of the citizens of Macau. At the same time, the complexity of the road network makes zonings unobvious functional and mixes urban functions in the region. Therefore, through field surveys, the relevant data of the Macau Transport Bureau (DSAT) is combined to find out the current problems of the road traffic on the Macau Peninsula and analyze the strategy of optimizing the "public transport priority" public transportation prove system. At Last, regarding the citizen as the core and find out the relationship between passengers and the public transportation system to explore the future development direction of the road traffic planning and design of the Macau Peninsula will become the main direction of this study.
\end{abstract}

\section{Keywords}

The Macau Peninsula, Road Traffic, Public Transport Priority, Government Policy

\section{Research Motivation}

The road traffic planning problem of the Macau Peninsula has always been one of the most helpless social issues for the citizens. In order to protect the historical reserves, the road network form in the road traffic planning of the Macao Peninsula will basically follow the road network design pattern of the previous 
version as an extension to protect and avoid historical reserves. Compared with the historical relics in the Mainland which have developed as a tourist area, this planning form is relatively rare and quite unique in China and it also has a substantial effect on the protection of historical sites. However, the planning and design of this kinds of road network has a big problem: The travel needs of contemporary residents have not been taken into account. Therefore, this article will use the study of road traffic problems in Macau as a motivation to discuss the policy actions taken by the government in order to explore the future direction of road traffic and public transport system in Macau.

\section{Research Problem}

This article is going to take the existing problems in the Macau Peninsula, such as the road safety and the public transport system as the starting point for research, and at the same time conducts an overall analysis of the traffic problems in the Macau Peninsula through field surveys. Meanwhile, this article combines the government's "transit priority" policy with the practical actions to analyze the countermeasures of the Macau government's on road traffic safety, operation efficiency and quality improvement of the public transport system on the Macau Peninsula. At last, the citizen will be taken as the core and the forecast situation will be explored in the future direction of the traffic development.

\section{Research Method}

This article will use the field survey method in the form of field shooting, public interviews and field observations field research on road traffic safety and public transport system operation issues in the Macau peninsula. Meanwhile, through the statistics provided by the Macau Transport Bureau (DSAT), the release of relevant policies as well as collecting relevant data in educational interactive promotion activities, etc., to combine the data content in order to conduct on-site observations and policy comparisons. At the same time, combining relevant reference materials to conduct research question reflection and research results aggregation and conduct research based on the results. At last, according to the result, the related discussions will be led to follow-up recommendations.

\section{Research Result}

\subsection{The Road Traffic Problems on the Macau Peninsula}

As far as external evaluations are concerned, Macao's road traffic is narrow but orderly. The establishment of one-way streets has greatly increased the smoothness of roads in the Macao Peninsula, and at the same time, the traffic jams are also very rare. However, the field observations have found that the problems mainly focus on the public's travel needs for public transportation, the safety of public travel and the unreasonable setting of road widths due to the setting up of parking spaces. Therefore, the below will discuss the problems of road traffic facilities, traffic accidents, and pedestrian travel needs from the perspective of traf- 
fic issues on the Macao Peninsula.

\subsubsection{Problems in Setting up Road Traffic Facilities}

The most significant problems of road traffic facilities are the sidewalk problems caused by the unreasonable setting of the road width, such as the sidewalk width being too narrow, the setting of single sidewalks and the unreasonable setting of parking berths, which caused the road width to be further The problem of narrowing. Take the Rua de Cinco de Outubro streets as an example. From the Figure 1 and Figure 2 we can find that, there are no traces of sidewalks in the Rua de Cinco de Outubro streets. Pedestrians walk in the middle of the road and vehicles behind can only be reminded by whistle. As a result, due to the lack of parking space planning on both sides of the road, most residents' motorcycles and motor vehicles are parked on both sides of the road. Pedestrians have basically lacked space to walk and only one car can pass at a time on the road.

At the same time, from the Figure 3 we can know that the sidewalk on one side is too wide in The Haystack Street, as the result, the sidewalk cannot be installed on the other side. Because of the sidewalk close to the store along the street, pedestrians can only walk on the steps in front of the stores. The store owners along the street are therefore very dissatisfied, thinking that this behavior of pedestrians affects the daily life and operation of merchants.

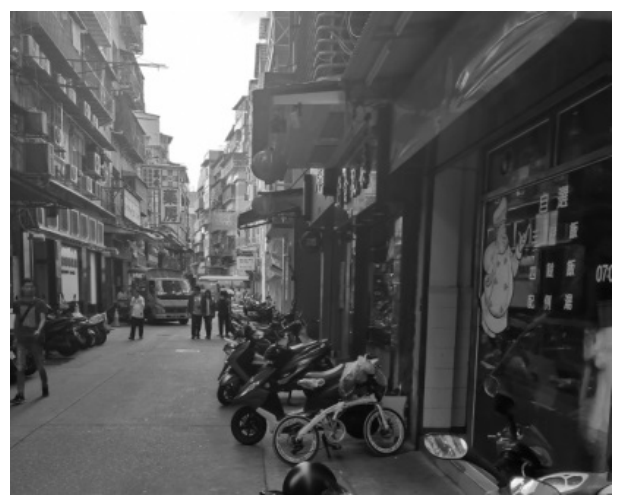

Figure 1. The parking situation of motorcycles on the Rua de Cinco de Outubro (Shooting for this study).

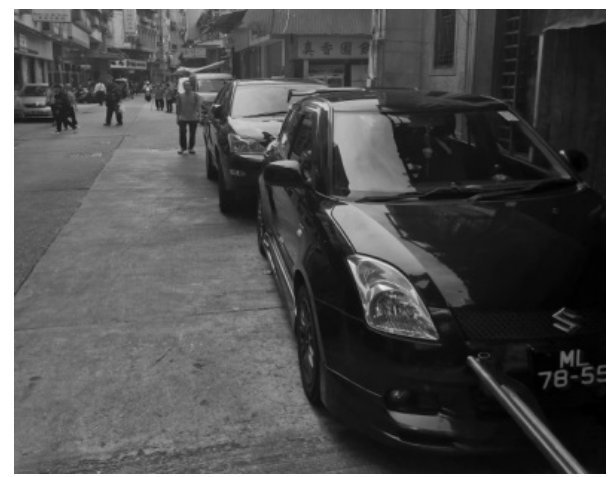

Figure 2. Parking situation of motor vehicles on the Rua de Cinco de Outubro (Shooting for this study). 


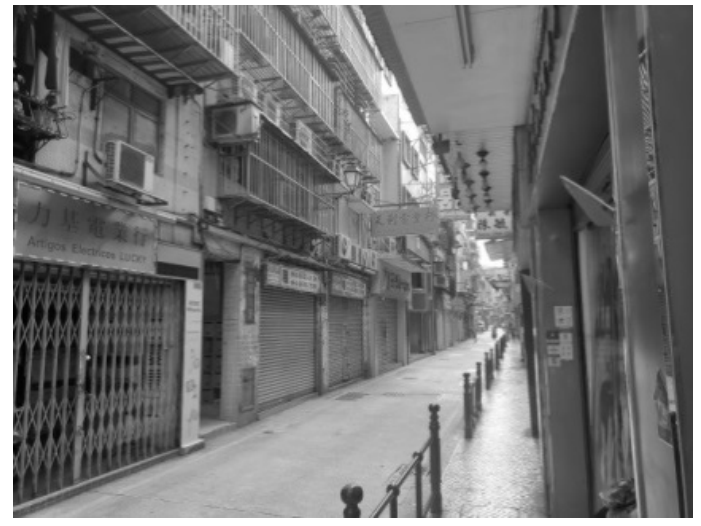

Figure 3. The side walk on the haystack street (Shooting for this study).

Through research, it can be found that the lack of on-street parking spaces and the random parking of motorcycles and motor vehicles are one of the reasons that the width of roads in Macao is not sufficient to meet the needs of pedestrian traffic and vehicle traffic. From the Figure 4 we can find that the number of motor vehicles and motorcycles is about $5-8$ times different from its corresponding parking space until 2019. Meanwhile, according to the Table 1, we can find that the parking fee on the roadside is lower than the parking space on fixed places which has increased parking pressure on both sides of the road.

Due to the limited area of the Macau Peninsula itself, the Macau Peninsula currently needs to pay attention to the issue of parking spaces. The development of the maximization method, on the other hand, needs to give full play to the role of the public transport system, promote green travel of citizens and reduce the use of motorcycles as well as the motor vehicles among the citizens.

\subsubsection{Traffic Accident}

According to the Figure 5, since 2013, the number of traffic accidents in Macau has reached more than 10,000 each year. Among them, the number of traffic accidents in 2013 was 15,077 and the number of deaths and injuries was 19. However, from 2016 to 2018, the total number of traffic accidents began to decline. The number of traffic accidents fell from 15,432 in 2016 to 14,717 in 2017, a year-on-year decrease of $4.1 \%$, and in 2018 , it fell to 13,764 , the decrease was $6.5 \%$. The number of injuries was fixed in the single digits.

The trend of the number of traffic accidents in Macau from 2015 to 2018 can be reflected that the number of traffic accidents in Macau is decreasing year by year. At the same time, it can be observed by the changes of motor vehicles and motorcycles in Macao from 2015 to 2018 occur to the relationship between the number of accidents and the number of motor vehicles and motorcycles.

According to the Figure 6, the number of motor vehicles began to change in 2016 , the year-on-year decrease was nearly $38.6 \%$ while the number of motorcycles also declined as the number of motor vehicles fell. Until 2018, the number of motor vehicles has fallen to 108,442 , a decrease of nearly $50 \%$ compared to 2015. 
Comparison of the number of motor vehicles and motorcycles and the number of parking spaces in Macau in 2019

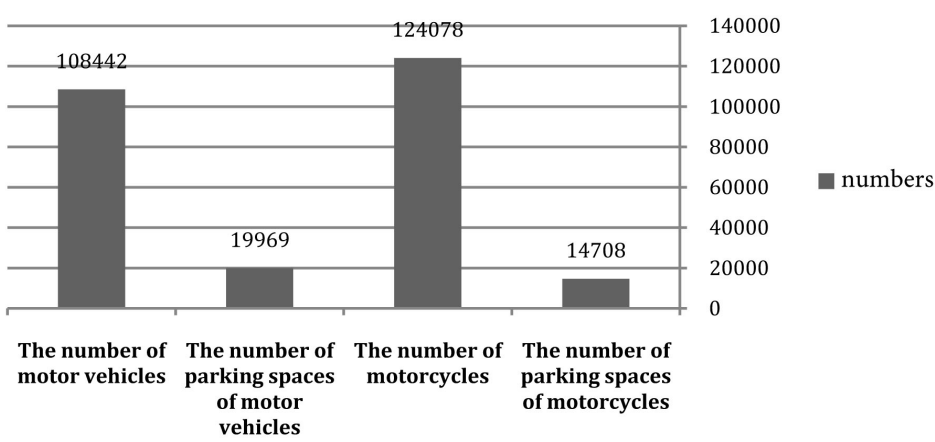

Figure 4. Comparison of the number of motor vehicles and motorcycles and the number of parking spaces in Macau in 2019 (data source: Macau Transport Bureau (DSAT), drawn by this study).



Figure 5. Trend of the number of traffic accidents in Macau from 2015 to 2018 (Data source: Macau Transport Bureau (DSAT), drawn by this study).

Number of motor vehicles in Macau from 2015 to 2018

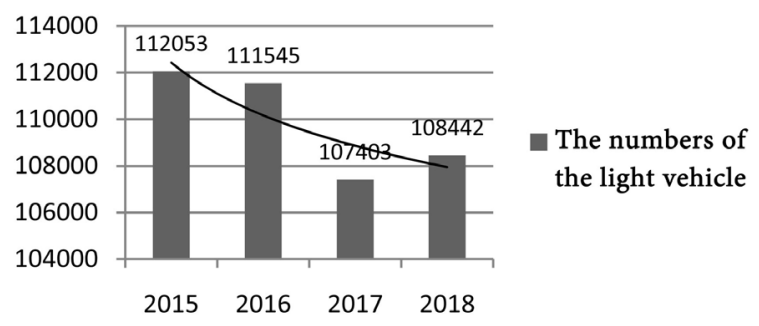

Figure 6. Trends of light motor vehicles in Macau 2015-2018 (Data source: Macau Transport Bureau (DSAT), drawn by this study).

Table 1. Macau parking meter "meter" charge standard (data source: https://is.gd/g4WVQf, drawn by this study).

\begin{tabular}{|c|c|c|c|}
\hline \multicolumn{4}{|c|}{ Parking Meters } \\
\hline Types of parking spaces & Maximum permitted parking time & Price type & Meter column color \\
\hline \multirow{3}{*}{ Light car } & 1 hour & MOP 10 & red \\
\hline & 2 hours & MOP 6 & yellow \\
\hline & 3 hours & MOP 3 & green \\
\hline \multirow{2}{*}{ Heavy vehicle } & 2 hours & MOP 10 & yellow \\
\hline & 5 hours & MOP 5 & gray \\
\hline \multirow{2}{*}{$\begin{array}{l}\text { Heavy and light } \\
\text { motorcycles }\end{array}$} & 2 hours & MOP 2 & yellow \\
\hline & 4 hours & MOP 1 & green \\
\hline
\end{tabular}


To sum up the Figure 5 and Figure 6, it can be observed that the number of traffic accidents in Macau is positively related to the changes in the number of motor vehicles and motorcycles. In fact, except for large and medium buses, freight cars and container trucks are not allowed to drive on the bustling street in the city center [1]. Therefore, the decline in the number of light motor vehicles has reduced the number of traffic accidents and casualties in Macau. At the same time, it also reflects that Macao residents have begun to travel on foot or by public transportation which shows their dependence on motor vehicles and motorcycles has gradually decreased.

\subsubsection{Public Transport Operation Configuration Issues}

According to data from the Macau Transport Bureau (DSAT), Macao residents' satisfaction with the Macau public transport system is between 6.5 and 7.5 (out of 10 points). The main dissatisfaction lies in the following points: the rapidly station passing buses running form and detour problems, comfort of the buses as well as the issues of the shift management and punctuality of buses.

Limited by the complex and messy road network form of the Macau Peninsula is difficult to reconfigure land types in other areas outside the historical old urban area which cannot achieve industrial transformation. Therefore, the functional zoning of the Macau Peninsula is not very obvious, and the daily activities of tourists who come to the Macau Peninsula and residents in Macao begin to mix up. In the Macau Peninsula bus system, the arguments between tourists and residents in Macau often occur due to congestion. At the same time, the commuters' commute was affected by the large number of passengers and the public transportation could not be deployed.

At the same time, as the Figure 7 shows that there are also exists the problem such as the traffic jams and delays caused by major races such as the Grand Prix Challenge. As a result many drivers take the measure such as rapidly station passing buses running form in order to reduce the driving time which will increase the dissatisfaction of the passengers.

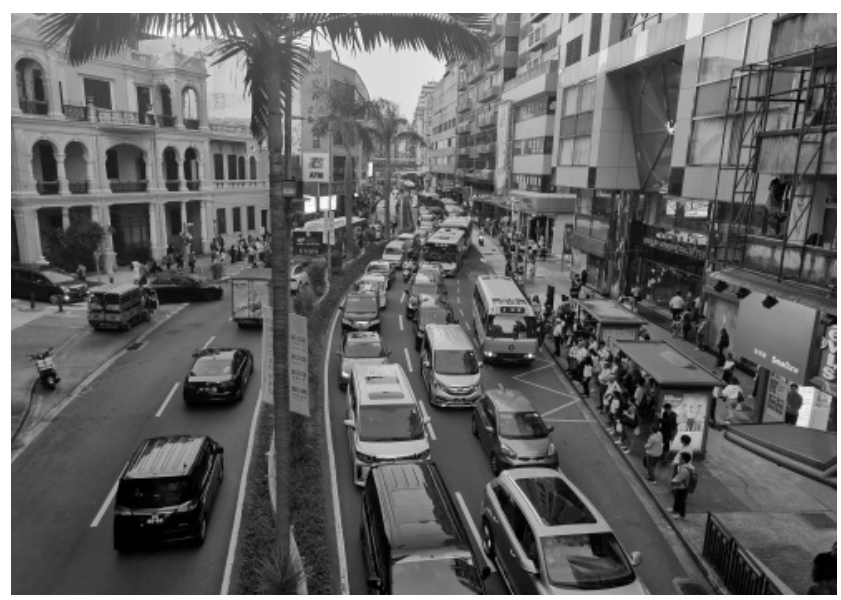

Figure 7. Traffic jam on the grand prix at the Rua do campo street (Shooting for this study). 
On the one hand, the bumps and swings inside the bus caused by acceleration and detours make passengers particularly dissatisfied with the bus driver's driving style. On the other hand, the bus driver's use of rapidly station passing buses driving form and detour driving makes the dissatisfaction of the passengers who are waiting in the station can't take the bus in time which has affected the commuting time. As a result, citizens' recognition of the management and deployment of the bus system gradually decreases.

Based on the above statement of problems on the roads and public transportation system of the Macao Peninsula, the road traffic characteristics of the Macao Peninsula can be summarized as follows: 1) High density and complexity of road network. 2) Narrow roads and low degree three-dimensional public transportation. 3) Road traffic on the Macau Peninsula is greatly affected by terrain. 4) The public transport play an important role in the Macau transport system. 5) The overall road traffic management in Macau is more orderly [2].

\subsection{The Discussion on Macau Government's "Transport Priority" Strategy}

In fact, according to the Table 2, it can be observed that the public's demand for public transportation is increasing. Therefore, the Macau government is now adopting a public transportation improvement strategy_ “Transport Priority"to encourage more citizens to use bus services, reduce the number of motor vehicles to ensure the safety of Macao citizens and at the same time to solve the traffic congestion and promote the green travel of the citizens.

Therefore, in order to improve the efficiency of public transportation management, the Macau government has carried out general plans for bus routes and divided buses into follow four levels: express buses, arterial buses, general buses, and shuttle buses. Among them, the express bus adopts a hop-stop operation to speed up the efficiency of bus operation. The main road bus connects the

Table 2. Macau bus passengers number from 2011 to 2019 (June) (Data source: https://is.gd/tEb4ZL, drawn by this study).

\begin{tabular}{cccc}
\hline \multicolumn{4}{c}{ Statistics on public bus passengers } \\
\hline years & $\begin{array}{c}\text { Total number of passengers } \\
(100 \text { million })\end{array}$ & $\begin{array}{c}\text { Daily average number of } \\
\text { passengers (100 million })\end{array}$ & $\begin{array}{c}\text { Daily average } \\
\text { passengers growth rate }\end{array}$ \\
\hline 2011 & 1.37 & 37.13 & $\uparrow 7.22 \%$ \\
2012 & 1.56 & 42.72 & $\uparrow 15.05 \%$ \\
2013 & 1.71 & 46.90 & $\uparrow 9.79 \%$ \\
2014 & 1.86 & 50.73 & $\uparrow 8.17 \%$ \\
2015 & 1.96 & 53.75 & $\uparrow 5.96 \%$ \\
2016 & 2.04 & 55.45 & $\uparrow 3.16 \%$ \\
2017 & 2.11 & 57.77 & $\uparrow 4.17 \%$ \\
2018 & 2.15 & 58.82 & $\uparrow 1.83 \%$ \\
As of & 1.11 & 61.54 & $\uparrow 5.41 \%$ \\
June 2019 & & & \\
\hline
\end{tabular}


major stations to meet the needs of passenger at large transportation stations and the general bus goes deep into the lives of residents and is responsible to connect the residential area and the work area of the residents. [3] In the form of hierarchical management and hierarchical operation of the bus, the operation and management of the entire bus system is well organized. Seamless integration of time, information, and services to improve the operational efficiency of the public transportation system [4]. At the following articles, two examples of the "bus priority" will be showed to summed up the aim and the desired effect of the government of the Macao public transport system.

\section{1) Up and down yellow dotted line}

After listening to the opinions of the taxi industry and the public, the Macau government took into account the needs of the taxi industry, drivers and passengers. As the Figure 8 shows that The Up and down yellow dotted lines were set up to test the trial implementation of the dotted line for taxi pick-up and drop-off on roads.

On the one hand, This line facilitates the temporary parking of taxis and the temporary parking of private cars. On the other hand, it can avoiding accidents of passengers and pedestrians caused by the random parking of taxis and private cars, and avoid the loss of additional costs for passengers due to the inability to find a fitness location to stop the passengers. In the official website, the Transport Bureau has opened a suggestion storage place of the yellow dotted line to facilitate the public to comment on the implementation of the yellow dotted line in order to make adjust in time.

\section{2) The Bus Priority lane}

In recent years, the per capita use of road space in Macau has decreased, and the number of passengers on public buses has increased significantly. In order to improve the efficiency of buses operating, the Macau government has opened The Bus Only lane on the Barra-Linmaotang section. Only buses are allowed in the lanes and motor vehicles and electric vehicles will be fined when they enter bus lanes in the running time.

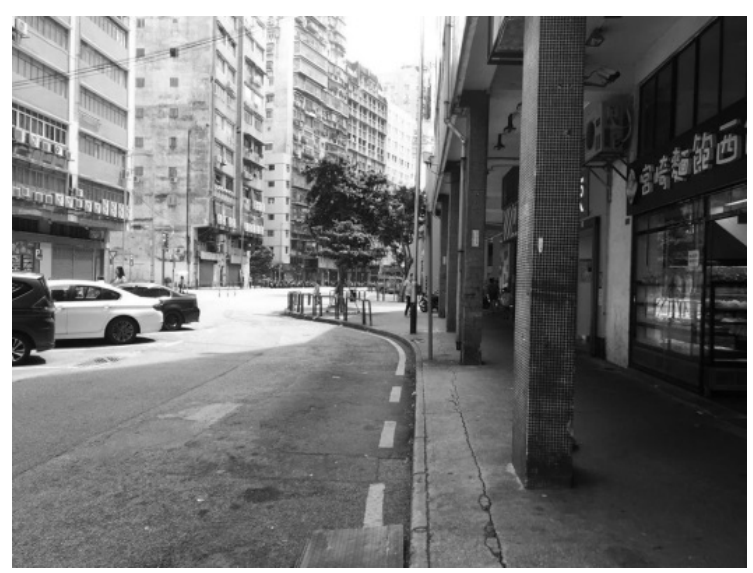

Figure 8. Yellow dotted line on the main road of Rua da Ribeira do Patane (Data source: https://is.gd/b1hTFU, 2019.10). 
The Barra-Linmaotang section of a huge success and its benefits mainly include: 1) Improving the number of buses and passengers an overall increase of $10 \%-15 \%$. 2) Reduction of driving time compared to the original travel time decreased by $7 \%-12 \%$. 3) The proportion of traffic accidents using bus lanes is smaller than that of non-bus priority lanes. The ratio of pedestrians is 1:1.27, while the ratio of pedestrian accidents is $1: 1.22$ and the ratio of injured is $1: 1.52$.

At the same time, the Macau government plans to set up a second bus priority lane on the Avenida do Coronel Mesquita. With reference to the benefits of the Barra-Linmaotang section bus lane, the Avenida do Coronel Mesquitabus lane is expected that the following benefit requirements can be achieved: 1) This section needs to reduce the average travel time of the bus by about $30 \%$ compared to the original. 2) It needs to ensure the safety of pedestrians. 3) The lane has to reserve the left-turn space for general vehicles. 4) The lane needs to reserve the general vehicles parking as more as possible at night.

According to the two cases of the public transport optimization measures, the Macau government s idea of optimizing public transportation issues can be summarized. In the process of optimizing the public transportation system, the Macau government regards the citizens as the cores and uses the actual operation of the public transportation system as the starting point to explore the problems, set up public transportation optimization facilities and experimental investigations with "priority development of public transportation" as the main purpose of the action. On the one hand, it can ensure that the bus system is operating under reasonable conditions in the maximize efficiency which can improve the punctuality of public transportation and at the same time increase the maximum passenger capacity of public transportation. On the other hand, through the hierarchical management mode of public transportation, the operation of the public transportation system is made more efficient which can improve the sense of identity of the residents of Macau.

\section{Research Discussions and Follow-Up Recommendations}

The Macau government has specially set up a traffic education section and knowledge of a driver's check of the vehicle's condition before driving on the website for the public and drivers to learn about road safety. Meanwhile, the government plans to introduce the road travel safety education to students' education in non-college schools such as kindergartens and elementary schools. At the same time, as the Figure 9 shows that a traffic safety theme publicity activity called "Traffic Safety Carnival” was held in the Praça do Tap Seac. Traffic safety publicity and education can be said to run through citizens in daily life.

What's more, the intelligent systems, Alibaba Cloud Computing and big data can be used to sharing of data on various transportation facilities in order to improve the strategic efficiency of the public transportation system optimized by the Macau government's transport information sharing. Therefore, the government needs to ensure the transparency of the data and within the accepted range and at the same time provides real-time traffic information on the Macau Pe- 
ninsula to the greatest extent in order to meet the needs of citizens for traffic information as much as possible.

However, according to the Figure 10 and Figure 11, There is an interesting phenomenon among the passengers group: Most passengers prefer to stand on the first half of the bus when there is much space in the second one because of the fact that mostly of them are about to get off the bus or unwilling to squeeze forward to the upper compartment. As a result, too many passengers in the first half of the carriage make it impossible for the passengers who are in the station to board in a short time. Therefore, as one of the components, the behavior of passengers may also cause problems in the operation of the public transportation system. While the public transportation system meets the travel needs of passengers, passengers need to follow the principles of the operation of the public transportation system to ensure the smooth operation of the public transportation system [5].

\section{Research Conclusion}

According to the above passages, we can summarize the optimization strategy of

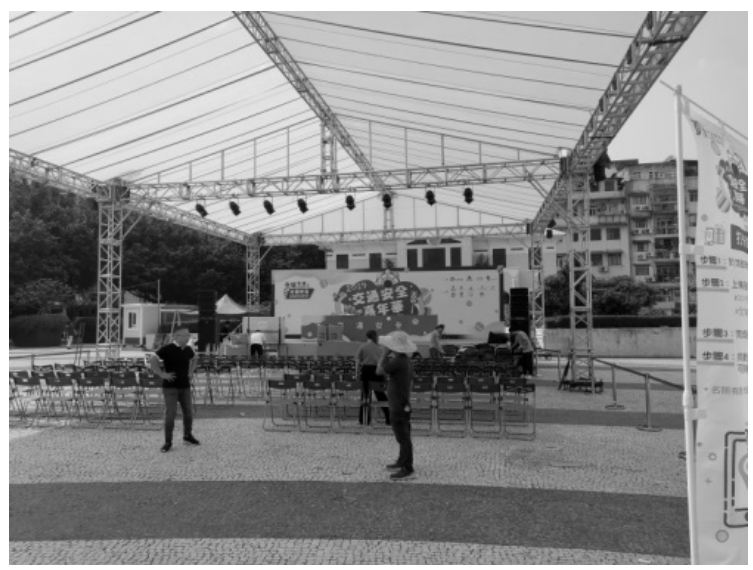

Figure 9. The Macau traffic safety carnival (Shooting for this study).

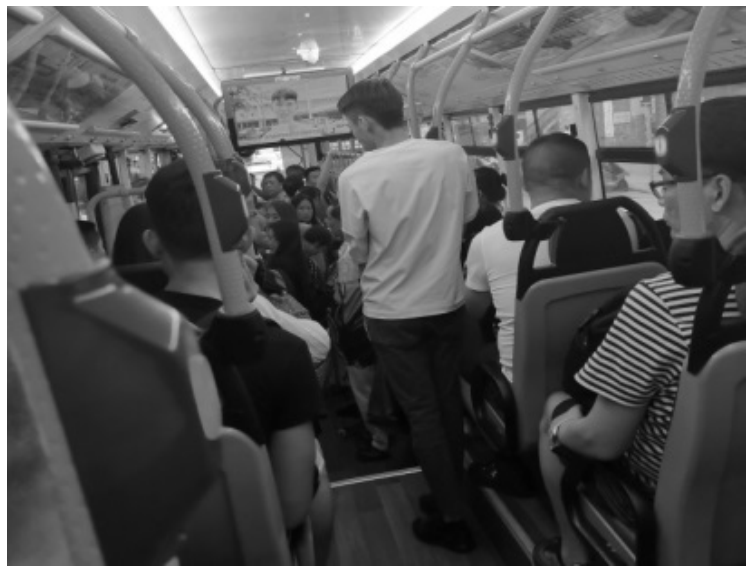

Figure 10. Crowded people in some compartments in front of the bus (Shooting for this study). 


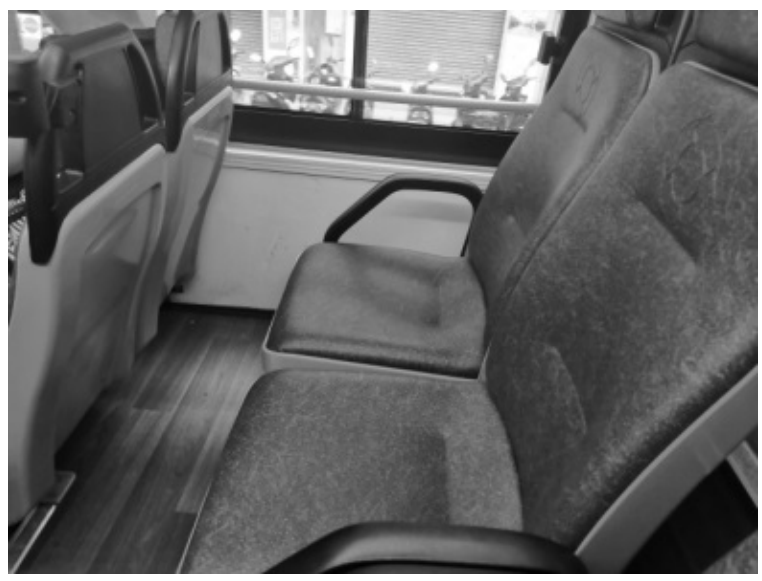

Figure 11. Empty seats in the second half of the bus (Shooting for this study).

Macau's public transportation system: the efficiency improvement and service improvement of Macau's public transportation system require the cooperation of citizens and the government to achieve maximum effectiveness. Meanwhile, popular science education in traffic safety has enabled Macau's road transportation and public transportation system to operate in an orderly manner subject to the compliance of citizens and drivers in order to realize the "ecologicalization" of public transportation in Macau.

\section{Conflicts of Interest}

The author declares no conflicts of interest regarding the publication of this paper.

\section{References}

[1] Li, J. (2003) A Big Landscape of Macau-Traffic. Hong Kong and Macau of the Motherland.

[2] Transportation Readiness Office of Guangdong Province (1995) Transportation Situation in Macau. 78-82.

[3] Ye, R.J., Wu, J.N. and Zhao, S.T. (2016) Research on Improving Macau Public Bus Services. Chongqing and World, 3, 2-5, 11.

[4] Zhao, Z.X. and Li, D. (2009) Discussion on the Reform of Macau Public Bus Service Mode. Planning and Implementation of Humanized Urban Comprehensive Transportation System-2009 Proceedings of China Urban Transport Planning Society, 467-472.

[5] Wu, T.Q. (2018) Reform and Opening up the Coast of the South China Sea-A New Chapter in the Development of Macau's Public Transport-Interview with the General Manager of Macau Bus Co., Ltd. Liang Meiling. Urban Public Transport, 12, 3. 